\title{
Tranexamic Acid versus Placebo for Prevention of Primary Postpartum Haemorrhage among High Risk Women Undergoing Caesarean Section in Abakaliki: A Randomized Controlled Trial
}

\author{
Nwafor Johnbosco Ifunanya*, Ibo Chukwunenye Chukwu, Obi Chuka Nobert, Onwe Blessing, \\ Ugoji Darlington-Peter Chibuzor, Onuchukwu Victor Uchenna
}

Department of Obstetrics and Gynaecology, Alex Ekwueme Federal University Teaching Hospital, Abakaliki, Nigeria

Email: *nwaforjohnbosco97@gmail.com

How to cite this paper: Ifunanya, N.J., Chukwu, I.C., Nobert, O.C., Blessing, O., Chibuzor, U.D.-P. and Uchenna, O.V. (2019) Tranexamic Acid versus Placebo for Prevention of Primary Postpartum Haemorrhage among High Risk Women Undergoing Caesarean Section in Abakaliki: A Randomized Controlled Trial. Open Journal of Obstetrics and Gynecology, 9, 914-922.

https://doi.org/10.4236/ojog.2019.96089

Received: May 27, 2019

Accepted: June 25, 2019

Published: June 28, 2019

Copyright $\odot 2019$ by author(s) and Scientific Research Publishing Inc. This work is licensed under the Creative Commons Attribution International License (CC BY 4.0).

http://creativecommons.org/licenses/by/4.0/

\begin{abstract}
Objective: To evaluate the efficacy of tranexamic acid for prevention of postpartum haemorrhage among women undergoing cesarean section who were at high risk of postpartum hemorrhage. Materials and Method: This was a double blind randomized controlled trial conducted at the Alex Ekwueme Federal University Teaching Hospital Abakaliki from January 2016 to December 2017. One hundred and sixty-eight parturients at high risk of postpartum haemorrhage who underwent caesarean section were randomly assigned to receive either tranexamic acid or placebo prior to skin incision. Results: The result of the study showed that the need for additional uterotonic was higher in women in the placebo arm when compared with women in the tranexamic arm of the study (7.4\% versus $33.3 \%$, respectively). The incidence of primary post-partum hemorrhage (blood loss $>1000 \mathrm{ml}$ ) was significantly lower in the tranexamic acid group compared to placebo group (11.9\% versus $50 \%$, respectively, P-value $<0.0001)$. Conclusion: Intravenous tranexamic acid given prior to skin incision at caesarean section reduced the need for additional uterotonics and incidence of primary postpartum among high risk women.
\end{abstract}

\section{Keywords}

Tranexamic Acid, Maternal, Mortality, Postpartum, Haemorrhage

\section{Introduction}

Postpartum hemorrhage $(\mathrm{PPH})$ is among the leading causes of maternal mor- 
bidity and mortality worldwide [1].

It is reported that PPH accounts for nearly $25 \%$ of maternal deaths and approximately $12 \%$ survivors after PPH suffers from severe postpartum anemia [2] [3]. Although there has been a remarkable improvement in the prevention of $\mathrm{PPH}$ in recent years, deaths due to PPH remain relatively common in developing countries like Nigeria [4] [5].

The majority of maternal deaths and complications attributable to postpartum haemorrhage could be prevented or minimized with timely access to medications and emergency care [5]-[18]. The incidence of PPH according to a recent study is $1.2 \%$ [8]. Although the majority of women who experience postpartum haemorrhage complications have no identifiable clinical or historical risk factors, some high risk factors such as grand multiparity and multiple gestation are associated with an increased risk of bleeding after birth [5]-[13]. Up to 75\% of PPH cases are caused by uterine atony [12]. However, the cases of mortality due to obstetric haemorrhage are mainly related to other causes of PPH [15]. Uterine atony was found only in $6.4 \%$ of cases of maternal death related to obstetric haemorrhage [16]. Other conditions such as abruption, placenta praevia, ruptured uterus, retained placenta, morbidly adherent placenta, vaginal and cervical trauma, inverted uterus, bleeding during and after caesarean section (CS) are the cause of the vast majority of maternal deaths [17] [18] [19] [20]. Considerable efforts to assure wide-spread access to uterotonics have been successful and the majority of women receive prophylactic uterotonics during childbirth [18]. Current methods used to prevent PPH include active management of the third stage of labour, uterotonics and prostaglandins [20]. Wide use of active management of labour is supported by a Cochrane review that showed reduced incidence of $\mathrm{PPH}$ greater than $1000 \mathrm{~mL}$ with this intervention [14]. However, the issue of maternal death due to $\mathrm{PPH}$ remains unresolved in low-resource settings like Nigeria despite widespread use of uterotonics. Attempts to address the problem need to go beyond the use of uterotonic drugs.

Tranexamic acid is an effective agent for the reduction of blood loss, which has been widely used in various areas of medicine [6]-[20]. It has been used to decrease blood loss for many years in cases of haemorrhage, and is reported to reduce intraoperative and postoperative blood loss [18].

The recent report of World Maternal Antifibrinolytic (WOMAN) trial showed that tranexamic acid reduces death due to bleeding from $1.9 \%$ to $1.5 \%$ in women with postpartum haemorrhage with no adverse effects [12]. Prophylactic use of tranexamic acid rather than waiting for a diagnosis of PPH is supported by evidence from the Clinical Randomization of an Anti-fibrinolytic in Significant Haemorrhage (CRASH-2) study which found that tranexamic acid was more effective the earlier it was administered in decreasing death due to bleeding in trauma patients [18]. Additionally, tranexamic acid has been shown to reduce bleeding during cesarean delivery as well as the need for additional uterotonic agents [19]. However, most studies have been performed in women with low risk for PPH and have not focused on assessing the effects of tranexamic acid in 
high-risk women.

This study aims to compare the effects of tranexamic acid with high dose oxytocin infusion in women at high risk of $\mathrm{PPH}$ following caesarean section.

\section{Materials and Method}

This double blinded, randomized, controlled trial was conducted at the Alex Ekwueme Federal University Teaching Hospital Abakaliki, Southeast, Nigeria, from January 2016 to December 2017, after approval of the study by hospital ethical committee. Pregnant women who had at least one risk factor for PPH and who were to undergo elective or emergency cesarean delivery were eligible for inclusion in the study after obtaining informed consent. The risk factors considered were hypertensive disorders in pregnancy, augmentation of labour, failed induction of labour, chorioamnionitis, placenta praevia, abruptio placentae, polyhydramnious, multiparity $(>4)$, previous postpartum haemorrhage, coexisting fibroids, fetal macrosomia, obstructed labour, multiple gestation, and previous caesarean section. The exclusion criteria for the study were history of cardiac, renal and liver diseases, bleeding disorders, history of any thrombogenic episodes, anticoagulant use and known allergy to tranexamic acid.

One hundred and sixty-eight women participated in the study (Figure 1). All caesarean section were done either by the consultant obstetrician or Senior registrar in Obstetrics and Gynaecology. Randomization was performed using computer-generated random numbers. At the beginning of the study, a container was filled with opaque envelopes, each containing one sheet of paper labelled with either a $\mathrm{T}$ or a $\mathrm{P}$ written on it with their code numbers. Eligible women were requested to randomly choose an envelope from the container. The selected envelope was opened by the anesthesiologist in charge of the case, who prepared the appropriate drug. Patients and obstetricians were masked to group allocation. According to group assignment, either $1 \mathrm{~g}(10 \mathrm{~mL})$ tranexamic acid $(500$

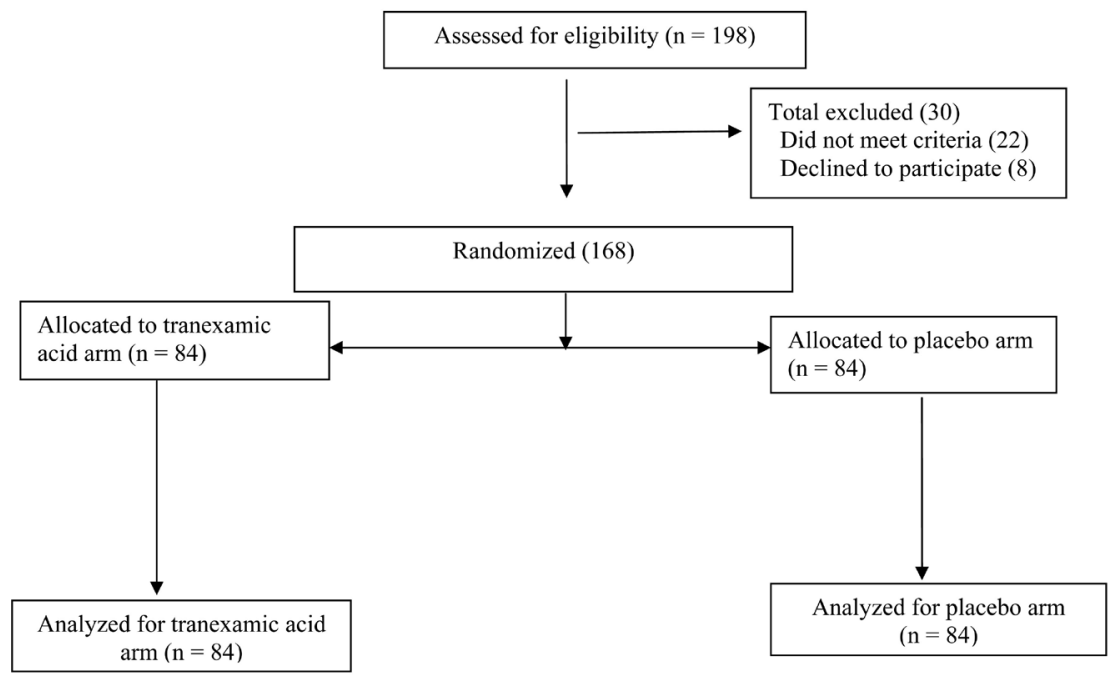

Figure 1. The figure shows the flow of patients through the study. 
mg Cyclocapron per $5 \mathrm{ml}$ ampoule; stored in a dry container at $15^{\circ} \mathrm{C}-30^{\circ} \mathrm{C}$ ) diluted in $10 \mathrm{~mL}$ of $0.9 \%$ normal saline (group $\mathrm{T}$ ) or $20 \mathrm{ml}$ of $0.9 \%$ normal saline was slowly administered intravenously over a 5-minute period (group P), 10 minutes before skin incision. As soon as the umbilical cord is clamped after delivery, all patients received an infusion of 40 IU oxytocin in 1 litre of normal saline over 3 hours. Additional uterotonic drugs at any time during the surgery (in case of increased capillary ooze or unsatisfactory uterine tone towards the end of uterine closure) or within the first $24 \mathrm{~h}$ after delivery (in case of increased postoperative vaginal bleeding, defined as a change of more than three fully soaked pads in any one hour) was administered. In case of increased bleeding, treatment according to the postpartum haemorrhage protocol was instituted. The requirement for additional uterotonics was recorded from the time of delivery for $24 \mathrm{~h}$.

The need for perioperative blood transfusion (after excessive perioperative bleeding or postoperative hemoglobin $<8 \mathrm{~g} / \mathrm{dl}$ ), total blood loss during surgery, postoperative hemoglobin at $48 \mathrm{~h}$, or any adverse events in the mother were also noted.

Calculated estimated blood loss (in litres) was derived by multiplying the calculated maternal blood volume by the percent of blood lost.

Calculated maternal blood volume (in litres) is calculated using Nadler formula [21]:

$$
\left(0.3669 \times \mathrm{H}^{3}\right)+(0.03219 \times \mathrm{W})+0.6041
$$

where $\mathrm{H}$ is height in meters and $\mathrm{W}$ is weight in kilograms.

Percent of blood volume lost $=$ \{preoperative $\mathrm{Hb}$ - postoperative $\mathrm{Hb}\} /$ preoperative $\mathrm{Hb}$.

where, $\mathrm{Hb}$ is Haemoglobin.

On discharge, patients who received tranexamic acid were counselled on symptoms and signs of a thromboembolic event and were instructed to contact the investigators immediately if any occurred. All patients were examined for thromboembolic events at the 2- and 6-week follow-up visits.

Demographic characteristics, risk factor(s) for postpartum haemorrhage, the indication(s) for cesarean delivery, and preoperative hematocrit levels within the $24 \mathrm{~h}$ before delivery (in the absence of significant preoperative bleeding) were recorded in the data. Data sheets were completed for all assigned women before entering the information into a database.

\subsection{Outcome Measures}

Primary outcome measure was the need for additional uterotonics within 24 hours of delivery while the secondary outcome measures were estimated blood loss, excessive blood loss (>1000 ml), and blood transfusion requirement.

\subsection{Sample Size Calculation}

Sample size was calculated using data from Cochrane systematic review that showed the risk of post-partum blood loss $>400 \mathrm{~mL}$ was $14.44 \%$ in women who 
received TXA, in contrast to $32.38 \%$ in women who did not, and EpiInfo version 7.0, setting the power at $90 \%$, the two-sided confidence level at $95 \%$ and $10 \%$ patients drop rate. Calculation according to these values, the number of women needed to produce a statistically acceptable figure was 84 in each group. Therefore, one hundred and sixty-eight women (168) were recruited for the study.

\subsection{Statistical Analysis}

Data were collected, tabulated then statistically analysed using the Statistical Package for Social Sciences (SPSS) computer software version 22. Numerical variables were presented as mean \pm standard deviation (SD), while categorical variables were presented as number and percentage. Chi-square test $\left(\mathrm{X}^{2}\right)$ was used for comparison between groups as regard categorical variables. Student t-test was used for comparison between groups as regard continuous variables. A difference with a $\mathrm{P}$ value $<0.05$ was considered statistically significant.

\section{Results}

The two studied groups were matched with no significant difference between the study and control groups regarding mean age, body mass index (BMI) and gestational age (Table 1), risk factors for postpartum haemorrhage and indications for caesarean section (Table 2 and Table 3).

There was no statistically significant difference between mean preoperative haemoglobin in both arms of the study but the 48 hour postoperative haemoglobin was significantly higher in women given tranexamic acid (10.5 \pm 1.6 , P-value $<0.0001)$ when compared to placebo group $(7.8 \pm 1.2)$ (Table 4).

Calculated blood loss was significantly lower in the tranexamic acid arm of the study ( $450 \pm 125 \mathrm{ml}$, P-value $<0.0001$ ) when compared those in the placebo arm of the study $(820 \pm 118 \mathrm{ml})$ (Table 4$)$.

The incidence of primary post-partum hemorrhage (blood loss $>1000 \mathrm{ml}$ ) was significantly lower in the tranexamic acid group compared to control group $(11.9 \%$ versus $50 \%$, respectively, P-value $<0.0001)$ (Table 4 ). Similarly there the need for additional uterotonic was higher in women in the placebo arm when compared with women in the tranexamic arm of the study (7.4\% versus $33.3 \%$, respectively, P-value $<0.0001$ ) (Table 4). The need for blood transfusion was significantly lower in the tranexamic acid arm (6\%) when compared with placebo arm of the study (14.3\%) (Table 4).

\section{Discussion}

Postpartum haemorrhage (PPH) is a common and potentially life-threatening complication of delivery. Uterotonics after birth are the only intervention that has been shown to be effective for PPH prevention. However despite widespread use of uterotonics, death from postpartum haemorrhage remains an issue particularly in developing countries like Nigeria. Further advances in this field are important, especially the identification of safe, easy to use and cost-effective regimens. 
Table 1. Demographic comparison of two groups.

\begin{tabular}{cccc}
\hline Variable & $\begin{array}{c}\text { Tranexamic acid group } \\
(\mathbf{n}=\mathbf{8 4})\end{array}$ & $\begin{array}{c}\text { Placebo group } \\
(\mathbf{n}=\mathbf{8 4})\end{array}$ & P-value \\
\hline Age (years) & $28.2 \pm 5.2$ & $28.6 \pm 5.4$ & 0.51 \\
Parity & $2.0 \pm 1.1$ & $1.8 \pm 1.5$ & 0.63 \\
BMI (kg/m $\left.{ }^{2}\right)$ & $25 \pm 1.4$ & $25 \pm 1.6$ & 0.22 \\
Gestational age (years) & $38 \pm 1.5$ & $38 \pm 1.3$ & 0.88 \\
\hline
\end{tabular}

Table 2. Risk factors for postpartum haemorrhage.

\begin{tabular}{cccc}
\hline Variables & $\begin{array}{c}\text { Tranexamic acid group } \\
\mathbf{n}=\mathbf{8 4}(\%)\end{array}$ & $\begin{array}{c}\text { Placebo group } \\
\mathbf{n}=\mathbf{8 4}(\%)\end{array}$ & P-value \\
\hline Hypertension in pregnancy & $10(11.9)$ & $12(14.3)$ & 0.82 \\
Induction of labour & $20(23.8)$ & $22(26.2)$ & 0.86 \\
Oxytocin augmentation & $15(17.9)$ & $18(21.4)$ & 0.70 \\
Chorioamnionitis & $5(5.95)$ & $3(3.6)$ & 0.99 \\
Placenta previa & $6(7.14)$ & $4(4.8)$ & 0.74 \\
Abruptio placentae & $1(1.2)$ & 0 & 0.99 \\
Polyhydramnios & 0 & $1(1.2)$ & 0.99 \\
Fibriods coexisting in pregnancy & $14(16.7)$ & $18(21.4)$ & 0.55 \\
Multiparity ( $\geq 5)$ & $28(33.3)$ & $22(26.2)$ & 0.39 \\
Fetal macrosomia & $16(19.1)$ & $14(16.7)$ & 0.84 \\
Obstructed labour & $4(4.8)$ & $2(2.4)$ & 0.98 \\
Previous postpartum haemorrhage & $3(3.6)$ & $2(2.4)$ & 0.99 \\
\hline
\end{tabular}

Table 3. Indications for caesarean section.

\begin{tabular}{cccc}
\hline Variables & $\begin{array}{c}\text { Tranexamic acid group } \\
\mathbf{n}=\mathbf{8 4}(\%)\end{array}$ & $\begin{array}{c}\text { Placebo group } \\
\mathbf{n}=\mathbf{8 4}(\%)\end{array}$ & P-value \\
\hline Severe preeclampsia & $20(23.4)$ & $24(28.6)$ & 0.59 \\
Fetal distress & $6(7.1)$ & $5(5.9)$ & 0.99 \\
Lack of progress in labour & $28(33.3)$ & $27(32.1)$ & 0.92 \\
Failed vaginal birth after caesarean & $4(4.8)$ & $3(3.6)$ & 0.99 \\
Placenta previa & $6(7.1)$ & $5(5.9)$ & 0.99 \\
Failed induction of labour & $5(5.9)$ & $5(5.9)$ & 0.74 \\
Obstructed labour & $4(4.8)$ & $3(3.6)$ & 1.00 \\
Fetal macrosomia & $9(10.7)$ & $8(9.5)$ & 0.79 \\
Multiple gestation & $2(2.4)$ & $4(4.8)$ & 1.00 \\
\hline
\end{tabular}

Table 4. Surgical outcome.

\begin{tabular}{cccc}
\hline Variables & $\begin{array}{c}\text { Tranexamic acid group } \\
\mathbf{n}=\mathbf{8 4}(\%)\end{array}$ & $\begin{array}{c}\text { Placebo group } \\
\mathbf{n = 8 4}(\%)\end{array}$ & P-value \\
\hline Preoperative haemoglobin $(\mathrm{g} / \mathrm{dl})$ & $11.1 \pm 2.4$ & $12 \pm 2.6$ & 0.42 \\
Postoperative haemoglobin $(\mathrm{g} / \mathrm{dl})$ & $11 \pm 1.6$ & $7.8 \pm 1.2$ & $<0.0001$ \\
Calculated blood loss $(\mathrm{ml})$ & $450 \pm 125$ & $820 \pm 118$ & $<0.0001$ \\
Blood loss $>1000 \mathrm{ml}$ & $10(11.9 \%)$ & $42(50 \%)$ & $<0.0001$ \\
Required transfusion & $5(6 \%)$ & $12(14.3 \%)$ & 0.03 \\
Additional uterotonics & $6(7.1 \%)$ & $28(33.3 \% 0$ & $<0.0001$ \\
\hline
\end{tabular}

Studies have been done to ascertain whether tranexamic acid is effective and safe for preventing PPH after delivery in comparison to placebo or no treatment (with or without uterotonic co-treatment), or to uterotonic agents with variable 
results. In spite of the various measures to prevent blood loss during and after caesarean section, post-partum hemorrhage continues to be the most common complication seen in almost $20 \%$ of the cases, leading to increased maternal morbidity and mortality [12].

This study showed that the use of tranexamic acid led to reduction in total blood loss during caesarean section when compared with placebo (450 $\pm 125 \mathrm{ml}$ versus $820 \pm 118 \mathrm{ml}$, respectively). This is similar to the finding of a study done in Turkey which showed that mean estimated blood loss at 48 hours was significantly lower among women treated with tranexamic acid than among those in the placebo group ( $499.9 \pm 206.4 \mathrm{ml}$ vs. $600.7 \pm 215.7 \mathrm{ml}$, respectively) [18]. Studies in Egypt and India reported similar findings [19] [20].

Similarly this study showed that the incidence of primary postpartum haemorrhage (blood loss $>1000 \mathrm{ml}$ ) was lower in women that received tranexamic acid when compared with placebo. This finding correlates with the findings of studies in Turkey, Pakistan and India.

The use of tranexamic acid prior to skin incision during caesarean section was associated with significant reduction on the need for additional uterotonics in this study. This was also similar to the findings of studies carried out in Egypt, Turkey and India [18] [19] [20]. However in this study more oxytocin was used in women who received tranexamic acid when compared with a study done in Turkey. This is because this study involved high risk women unlike a study in Turkey where low risk women were involved.

Also in this study fewer women in tranexamic acid arm received blood transfusion when compared with the placebo group (5 versus 12 , respectively; P-value $=0.03$ ). This result is similar to that studies done in Pakistan, Turkey and India [17] [18] [19] but contradict the finding of a study done in Egypt that showed no significant difference in blood transfusion among women that received tranexamic acid and those that were given placebo [20]. This difference may be due to differences in population of women used in this study which are women at high risk of postpartum haemorrhage.

The major strength of this randomised, controlled study is its double blinded character. Centralized randomisation and strict data concealment were followed. Therefore, the results are at lower risk of bias. However, the study has some limitations. Firstly, the design of this study was not powered to show decreases in maternal death or number of invasive procedures, which are the ultimate goals of maternity treatment. The second limitation is that the tranexamic acid-related risk of thrombosis could not be evaluated in this study.

\section{Conclusion}

In conclusion, this study further confirmed that tranexamic acid can be used safely to reduce blood loss during casearean section. Tranexamic acid administration before skin incision during caesarean section was associated with significant reduction in incidence of primary postpartum haemorrhage and the need 
for additional uterotonics, improvement of postoperative hemoglobin, and reduction on the need for blood transfusion.

\section{Acknowledgements}

I thanked the management of the Alex Ekwueme Federal University Teaching Hospital for their support during the course of the study.

\section{Conflicts of Interest}

None.

\section{References}

[1] World Health Organization (2012) WHO Recommendations for the Prevention and Treatment of Postpartum Haemorrhage.

[2] Li, C., et al. (2017) Is Prophylactic Tranexamic Acid Administration Effective and Safe for Postpartum Hemorrhage Prevention? A Systematic Review and Meta-Analysis. Medicine, 96, e5653. http://www.md-journal.com https://doi.org/10.1097/MD.0000000000005653

[3] World Health Organization (2016) Maternal Mortality Fact Sheet. http://www.who.int

[4] Society of Gynaecology and Obstetrics of Nigeria (2004) Status of Emergency Obstetrics in Six State of Nigeria-A Need Assessment Report. http://www.sogon.org

[5] Ezegwui, H., Onoh, R., Ikeako, L., Onyebuchi, A., Umeora, O., Ezeonu, P. and Ibekwe, P. (2013) Investigating Maternal Mortality in a Public Teaching Hospital, Abakaliki, Ebonyi State Nigeria. Annals of Medical and Health Science Research, 3, 75-80. https://doi.org/10.4103/2141-9248.109511

[6] Sentilhes, L., Lasocki, S., Ducloy-Bouthors, A.S., Deruelle, P., Dreyfus, M., Perrotin, F., et al. (2015) Tranexamic Acid for the Prevention and Treatment of Postpartum Haemorrhage. BJA, 114, 576-587. https://doi.org/10.1093/bja/aeu448

[7] Viswanath, O., Santhosh, S. and Goldman, H. (2015) The Evolving Role of Prophylactic Use of Tranexamic Acid before Caesarean Section: Balance between Maternal Benefits and Unknown Neonatal Effects. Journal of Anesthesiology and Clinical Science, 4, 4. https://doi.org/10.7243/2049-9752-4-4

[8] Alifah, Z., Shamsir, A. and Suharjono, H.N. (2013) To Study the Role of Tranexamic Acid in Reducing Blood Loss during and after Caesarean Section in Sarawak General Hospital. Journal of Surgical Academia, 3, 46-50.

[9] Peitsidis, P. and Kadir, R.A. (2011) Antifibrinolytic Therapy with Tranexamic Acid in Pregnancy and Postpartum. Expert Opinion on Pharmacotherapy, 12, 503-516. https://doi.org/10.1517/14656566.2011.545818

[10] Davis, S. (2015) Tranexamic Acid for Postpartum Haemorrhage: A Review. Global Journal of Medical Research, 14, 26-29.

[11] Ramani, B. and Nayak, L. (2014) Intravenous 1 Gram Tranexamic Acid for Prevention of Blood Loss and Blood Transfusion during Caesarean Section: A Randomized Case Control Study. International Journal of Reproduction, Contraception, Obstetrics and Gynecology, 3, 366-369. https://doi.org/10.5455/2320-1770.ijrcog20140616

[12] WOMAN Trial Collaborators (2017) Effect of Early Tranexamic Acid Administration on Mortality, Hysterectomy, and Other Morbidities in Women with Post-Partum Haemorrhage (WOMAN): An International, Randomised, Double-Blind, Place- 
bo-Controlled Trial. The Lancet, 389, 2105-2116.

[13] Gobbur, V.R., Shiragur, S.S., Jhanwar, U.R. and Tehalia, M.J. (2014) Efficacy of Tranexamic Acid in Reducing Blood Loss during Lower Segment Caesarean Section. International Journal of Reproduction, Contraception, Obstetrics and Gynecology, 3, 414-417. https://doi.org/10.5455/2320-1770.ijrcog20140626

[14] Novikova, N., Hofmeyr, G.J. and Cluver, C. (2015) Tranexamic Acid for Preventing Postpartum Haemorrhage. Cochrane Database of Systematic Reviews, No. 6, CD007872. https://doi.org/10.1002/14651858.CD007872.pub3

[15] Bhavana, G., Abhishek, M.V. and Suneeta, M. (2016) Efficacy of Prophylactic Tranexamic Acid in Reducing Blood Loss during and after Caesarean Section. International Journal of Reproduction, Contraception, Obstetrics and Gynecology, 5, 2011-2016. https://doi.org/10.18203/2320-1770.ijrcog20161708

[16] Suseela, T.L., Jyothi, S.J., Rabbani, P. and Jhonsi, C. (2016) Randomized Controlled Trial of Tranexamic Acid among Parturients at Increased Risk for Postpartum Hemorrhage Undergoing Cesarean Delivery in a Tertiary Care Teaching Hospital at Rims Kadapa. Indo American Journal of Pharmaceutical Research, 6, 6101-6108.

[17] Maged, A.M., Helal, O.M., Elsherbini, M.M., Eid, M.M., Elkomy, R.O., Dahab, S., et al. (2015) A Randomized Placebo-Controlled Trial of Preoperative Tranexamic Acid among Women Undergoing Elective Cesarean Delivery. International Journal of Gynecology \& Obstetrics, 131, 265-268. https://doi.org/10.1016/j.ijgo.2015.05.027

[18] Gungorduk, K., Yildirim, G., Asicioglu, O., Gungorduk, O.C., Sudolmus, S. and Ark, C. (2011) Efficacy of Intravenous Tranexamic Acid in Reducing Blood Loss after Elective Cesarean Cection: A Prospective, Randomized, Double-Blind, Placebo-Controlled Study. American Journal of Perinatology, 28, 23-40. https://doi.org/10.1055/s-0030-1268238

[19] Shahid, A. and Khan, A. (2013) Tranexamic Acid in Decreasing Blood Loss during and after Caesarean Section. Journal of College of Physicians and Surgeons Pakis$\tan , 23,459-462$.

[20] Bhatia, K.S. and Deshpande, H. (2015) Role of Tranexamic Acid in Reducing Blood Loss during and after Caesarean Section. Medical Journal of Dr. D.Y. Patil Vidyapeeth, 8, 21-25. https://doi.org/10.4103/0975-2870.148830

[21] Mavis, N.S. (2010) Measurement of Blood Loss: Review of the Literature. Journal of Midwifery \& Women's Health, 15, 20-27. https://doi.org/10.1016/j.jmwh.2009.02.014 